\title{
Prikaz slučajeva bruceloze svinja u Istri tijekom 2018. i 2019. godine
}

\author{
M. Zdelar-Tuk, S. Špičići , S. Duvnjak, I. Reil, G. Kompes, B. Habrun i \\ S. Mudrić
}

\section{Sažetak}

Slučajevi bruceloze redovito se opisuju u zemljama centralne i zapadne Europe. Bruceloza svinja se po svojoj pojavnosti unatrag dva desetljeća smatra endemskom bolesti u kontinentalnom dijelu Hrvatske $\mathrm{u}$ kojem je razvijeno intenzivno i ekstenzivno svinjogojstvo. Tijekom 2018. i 2019. godine na području sjeverozapadne Istre, kao uzrok pobačaja i tijekom kontrole susjednih stada, potvrđena je bruceloza svinja prouzročena vrstom $B$. suis bv. $2 \mathrm{u}$ dva uzgoja. Dijagnostika bolesti provedena je serološkim pretragama, brucelinizacijom, bakteriološkom i molekularnim pretragama. Prema našim saznanjima, ovo je prvi opisani slučaj bruceloze domaćih svinja na području
Istarske županije i dokaz da se kontrola ove bolesti mora provoditi osobito u slučajevima pobačaja. S obzirom da ne postoje službeni statusi stada slobodnih od bruceloze svinja u R. Hrvatskoj, sa stanovišta sigurnosti, uzgajivači bi pri uvođenju novih rasplodnih svinja u uzgoj obvezno trebali provoditi prethodnu kontrolu životinje i uzgoja iz kojeg dolazi te tražiti garancije na ovu bolest. $S$ obzirom na sve veću popularnost ekstenzivnog načina uzgoja svinja, monitoringom bolesti u divljih životinja utvrdili bi se u pojedinim hrvatskim regijama i rizici i značenje prijenosa na domaće svinje.

Ključne riječi: Brucella suis, bruceloza, svinja, Istra, epidemiologija

\section{Uvod}

Bruceloza svinja je zoonoza rasprostranjena diljem svijeta, prouzročena $s$ tri (biovarovi 1, 2 i 3) od pet biovarova vrste Brucella suis (B. suis), koji uzrokuju infekcije domaćih i divljih svinja, ali i ljudi. Uzročnik infekcije su unutarstanične bakterije iz roda Brucella koje pripadaju $\alpha$-proteobakterijama, klasi vrlo raznolikih bakterija prilagodljivih novim uvjetima staništa. Brucella sp. je rod koji se trenutno sastoji od 13 vrsta (Scholz i sur. 2018., Ledwaba i sur., 2019.). Osim svinja, brucele inficiraju i domaće i divlje životinje poput krava, ovaca, koza, pasa (Godfroid, 2002.); morskih sisavaca, običnih voluharica, crvenih lisica, pavijana, žaba i riba, a izdvojene su i iz implantata ljudskih grudi (Al Dahouk i sur., 2007., Scholz i sur., 2008a., 2008.b, 2010., 2016., Whatmore i sur., 2014.,

Dr. sc. Maja ZDELAR-TUK, dr. med. vet., dr. sc. Silvio ŠPIČIĆ* , dr. med. vet., (dopisni autor, e-mail: spicic@veinst.hr), dr. sc. Sanja DUVNJAK, Irena REIL, dr. med. vet., Gordan KOMPES, dr. med. vet., Boris HABRUN, dr. med. vet., izvanredni profesor, Hrvatski veterinarski institut, Zagreb, Hrvatska; mr. sc. Slobodan MUDRIĆ, Ministarstvo poljoprivrede, Uprava za veterinarstvo i sigurnost hrane, Odjel Veterinarski ured Pula, Ispostava Poreč 
Cvetnić i sur., 2017., Muhldorfer i sur., 2017.).

Geografska rasprostranjenost i domaćini vrste $B$. suis variraju. Biovarovi 1 i 3 pogađaju uglavnom domaće (Sus scrofa domesticus) i divlje svinje (Sus scrofa) te prouzročeu infekcije u ljudi (Godfroid i sur., 2005., 2013.). Za razliku od spomenutih biovarova, biovar 2 je rijetko patogen za ljude i ograničen je na kontinentalnu Europu (Paton i sur., 2001., Lagier i sur., 2005., EFSA, 2009., Mailles i sur., 2017.). Divlja svinja i europski smeđi zec (Lepus europaeus) jedini su do sada dokazani rezervoari $B$. suis biovar 2 (Godfroid, 2002., Bergagna i sur., 2009., Cvetnić i sur., 2009., Muñoz i sur., 2010., Grégoire i sur., 2012.). Iako vrlo rijetko, B. suis bv. 2 može zaraziti goveda i konje, ali njezino epidemiološko značenje nije poznato (Andersen i Petersen, 1995., Cvetnić i sur., 2005., Szulowski i sur., 2013., Jaÿ i sur., 2014.). Unatoč sporadičnim epidemijama, zemlje Europske unije se smatraju slobodnima od bruceloze svinja $\mathrm{u}$ intenzivnoj svinjogojskoj proizvodnji. Međutim, B. suis bv. 2 je široko rasprostranjen $\mathrm{u}$ divljini, $\mathrm{s}$ obzirom na mogućnost kontakta što najviše ugrožava svinje u ekstenzivnoj proizvodnji (Cvetnić i sur., 2003., 2005., EFSA, 2009., Špičić i sur., 2010.). Povremeno se bruceloza ulaskom zaraženih svinja, hranom i/ili kontaminiranim sjemenom pojavljuje i u intenzivnom uzgoju svinja.

Bruceloza u svinja prouzročena B. suis, osobito biovarom 2 , očituje se sustavnim infekcijama i može prouzročiti kroničnu bolest (Díaz Aparicio, 2013., Poester i sur., 2013.). Bakterijemija traje nekoliko mjeseci, a $B$. suis se zadržava u maternici, prouzočeći kronični metritis (Alton, 1990., Megid i sur., 2010.). U nerastova su isto česte genitalne infekcije (epididimitis). Osim reproduktivnih poremećaja očituje se: pobačajem, smanjenjem veličine legla, avitalnom prasadi i neplodnošću (protrahirani pobačaj) (Megid i sur., 2010., Meirelles-Bartoli, 2012.).
Bruceloza svinja je endemska bolest $\mathrm{u}$ Hrvatskoj, a B. suis je prisutna u populaciji domaćih i divljih svinja u svim županijama u kojima se uzgajaju svinje (Cvetnić i sur., 2008., 2009., Spičić i sur., 2013., 2016.). Najviše je zastupljena na području Sisačkomoslavačke županije, osobito u području uz Park prirode Lonjsko polje i Posavini, oko rijeke Save, gdje ekstenzivan način držanja životinja omogućuje kontakt i parenje domaćih i zaraženih divljih svinja. $S$ obzirom na prirodne rezervoare bolesti i način širenja zabilježeni su slični slučajevi infekcije i u drugim europskim zemljama (Hars i sur., 2004., Leuenberger i sur., 2007., Muñoz i sur., 2010., Barlozzari i sur., 2015., Scholz i sur., 2018.).

Infekcija s B. suis bv. 2 je dijagnosticirana 2011. i u dva gospodarstva s intenzivnim uzgojem u Osječko-baranjskoj županiji (Cvetnić i sur., 2009.) s približno 1000 rasplodnih krmača te u Bjelovarskobilogorskoj županiji (Špičić, neobjavljeni podatci). Važno je napomenuti da je Hrvatska bila prva europska zemlja u kojoj je infekcija $B$. suis biovar 3 otkrivena u konja, svinja i divljih svinja (Cvetnić i sur., 2005., 2009.), a izdvojeni sojevi su se po svojim molekularnim, kulturelnim i biološkim osobinama razlikovali od svih do tada opisanih sojeva vrste B. suis (Špičić i sur., 2010., Duvnjak i sur., 2015., 2022.).

Prema našim saznanjima, bruceloza svinja u Istarskoj županiji do sada nije evidentirana te se ovim radom, prvi puta opisuju slučajevi bruceloze svinja u dva uzgoja svinja u Istri, odnosno na području dvije općine na sjeverozapadu Istre.

\section{Materijali i metode Opis slučaja}

U Hrvatskoj svaki pobačaj ili pojavu kliničkih znakova koji upućuju na brucelozu, obvezno je prijaviti ovlaštenom veterinaru koji uzima odgovarajuće uzorke te ih dostavlja ovlaštenom dijagnostičkom laboratoriju s ciljem dijagnostike bolesti. 
Tijekom 2018. i 2019. godine $u$ Laboratorij za bakterijske zoonoze i molekularnu dijagnostiku bakterijskih bolesti, Nacionalni referentni laboratorij za brucelozu Hrvatskog veterinarskog instituta u Zagrebu dostavljena su 62 uzorka krvi svinja s dva gospodarstva u Istarskoj županiji s područja općina Višnjan i Tar-Vabriga. Životinje su u ovom istraživanju držane poluekstenzivno, kombinirajući stajsko držanje i ograđene ispuste. Zbog pobačaja gravidnih krmača i reproduktivnih problema posumnjalo se na brucelozu. Prvo je provedena serološka pretraga krvi onih krmača koje su pobacile. Iste su, po pozitivnom nalazu testirane primjenom metode brucelinizacije. $\mathrm{Na}$ farmi na kojoj je bruceloza potvrđena u krmača koje su pobacile, serološki su testirani i nerastovi te ostale krmače i nazimice. Sve serološki pozitivne životinje izdvojene su iz stada te su prilikom klanja uzeti uzorci za bakteriološku pretragu.

\section{Serološka pretraga}

Tijekom 2018. godine na dva gospodarstva u Istarskoj županiji Rose Bengal testom pretražene su 54 krvi krmača, 5 nerastova i 1 nazimice, a u 2019. pretražili smo 2 krvi krmača (Slika 1). Dijagnostiku bruceloze temeljili smo na Rose Bengal testu (RBT) kao testu probira (Institut Pourquier, Montpelier, Francuska) te indirektnom imunoenzimskom testu ELISA (Ingesim Brucella Porcina, Ingenasa, Madrid, Španjolska) kao potvrdnoj serološkoj metodi. Pretrage su izvršene u skladu s važećom nacionalnom legislativom, a valorizacija rezultata imunoenzimskog testa izvršena je u skladu s preporukama proizvođača kita (Ingenasa, Madrid, Śpanjolska).

\section{Brucelinizacija}

Brucelinizacija je klasični kožni alergijski test uz primjenu pročišćenog proteinskog derivata brucelina, koji se nakon utvrđivanja pozitivnih seroloških reakcija može koristiti kao probirni ili kao potvrdni test. Rezultati se moraju tumačiti u odnosu na kliničke znakove, povijest bolesti i rezultate seroloških i bakterioloških pretraga. Test je proveden uporabom pročišćenog proteinskog derivata Brucellargene OCB, Synbiotics, Francuska. Brucelinizirano je 8 svinja za koje su prve utvrđene pozitivne serološke reakcije, u farmi s utvrđenim pobačajima.

\section{Bakteriološka pretraga}

Materijal za bakteriološku pretragu uziman je prilikom klanja svinja koje su reagirale pozitivno minimalno $\mathrm{s}$ jednom serološkom metodom. Prve svinje proslijeđene za klanje radi daljnje bakteriološke pretrage, bile su ujedno pozitivne i na pretragu metodom brucelinizacije. Zbog ekstenzivnog načina držanja, većinu svinja nije bilo moguće privesti klanju, jer su neke uginule, a jedan dio je i bio izlučen iz uzgoja bez uzimanja uzoraka za bakteriološku pretragu (podatci veterinarske inspekcije). Od svinja su uzimani reproduktivni organi (testesi, epididimis, uterus), limfni čvorovi (supramamarni, ingvinalni, mandibularni, mezenterijalni, perihepatički, ilijačni, portalni) te jetra. U 2018. godini bakteriološki je pretraženo 10 uterusa, 3 testesa s epididimisom, dvije jetre te skupni limfni čvorovi od ukupno 13 svinja, a tijekom 2019. pretraženo je 13 uterusa i skupni uzorak limfnih čvorova 13 serološki pozitivnih svinja.

Bakteriološka pretraga je provedena korištenjem selektivnih hranilišta, Brucella agar uz dodatak konjskog seruma, bacitracina, polymyxin B sulfata i hranilišta po Farrellu (Alton, 1988.). Inokulirane podloge smo inkubirali na $37^{\circ} \mathrm{C}$ na normalnoj atmosferi i usporedno na $10 \%$ $\mathrm{CO}_{2}$. Porast kolonija je tijekom sljedećih 8 dana svakodnevno provjeravan. Kolonije su zatim bile identificirane na osnovi morfologije (sitne, prozirne, konveksne, glatke) (Alton i sur., 1988.). 


\section{Molekularna pretraga}

Identifikacija vrste Brucella sp.

Sumnjive su kolonije bile podvrgnute identifikaciji "Bruce-ladder" pretragom (Garcia-Yoldi i sur., 2006.) koja u jednom koraku može se potvrditi točno o kojoj se vrsti brucela radi, uključujući sve biovarove terestrijalnih brucela (B. neotomae, B. abortus biovarovi 1, 2, 3, 4, 5, 6, 7, 9, B. melitensis biovarovi 1, 2, 3 i B. suis biovarovi 1, 2, 3, 4,5) i sojeve iz morskih sisavaca (B pinnipedialis i $B$ ceti) te vakcinalne sojeve $(B$. abortus S19, $B$. abortus RB51 i $B$ melitensis Rev.1). Pretraga je provedena sukladno referenci.

\section{Molekularna tipizacija izolata B. suis}

INgene Bruce-ladder Suis kit (Ingenasa, Španjolska) koristili smo za identifikaciju Brucella suis bv. 1-5 za sve izolate koji su u prethodnoj pretrazi bili identificirani na razini vrste. Pretraga je provedena prema uputi proizvođača, a očekivana veličina produkata umnožavanja za B. suis bv. 1 je 197 i 425 bp; za bv. 2278 i 548 bp; za bv. 3197 i 302 bp; za bv. 4197 i 611 bp; i za bv. 5 197, 278, i 611 bp.

\section{Rezultati}

\section{Serološka pretraga}

Tijekom 2018. godine na farmi $1 \mathrm{u}$ općini Višnjan, pozitivne serološke reakcije Rose Bengal testom ustanovljene su kod 34 od 36 pretraženih životinja. U 2019. godini na istoj farmi testirane su dvije krvi, od kojih je jedna bila pozitivna. Na farmi 2 (općina Tar-Vabriga) u 2018. godini od 24 životinje pretražene sa RBT pozitivno su reagirale 22 životinje dok tijekom 2019. godine serološki nije pretražena niti jedna životinja. Potvrdnim testom za brucelozu svinja ELISA (Ingesim Brucella Porcina, Ingenasa, Madrid, Španjolska) tijekom 2018. godine na farmi 1 od pretraženih 36 svinja pozitivnu reakciju su imale 33 svinje, a na farmi 2 od 24 testirane, pozitivne su bile 23 životinje. U 2019. na farmi 1 imunoenzimskim testom pretražene su dvije krmače: jedna je bila pozitivna, a na farmi 2, nije provedeno serološko testiranje (Tabela 1).

\section{Brucelinizacija}

Tijekom 2018. godine na farmi F1 brucelinizirano je 8 svinja koje su prve pobacile i temeljem seroloških pretraga pozitivno reagirale na brucelozu primjenom metoda RBT i ELISA. Ukupno je 7 svinja reagiralo pozitivno na aplikaciju brucelina u vidu edema, crvenila, bolnosti i centralne nekroze tkiva (Slika 2).

\section{Bakteriološka i molekularna pretraga}

U 2018. godini na bakteriološku pretragu s farme 1 dostavljeni su uzorci jetre, uterusa, testisa te skupnih limfnih čvorova 11 svinja. Brucela je izdvojena iz

Tabela 1. Serološke pretrage krvi svinja tijekom 2018. i 2019. godine

\begin{tabular}{|l|c|c|c|c|c|c|c|c|}
\hline Godina & \multicolumn{3}{|c|}{ 2018. godina } & \multicolumn{3}{c|}{ 2019. godina } \\
\hline Serološka metoda & \multicolumn{2}{|c|}{$\begin{array}{c}\text { Broj } \\
\text { pretraženih } \\
\text { krvi }\end{array}$} & $\begin{array}{c}\text { Broj } \\
\text { pozitivnih } \\
\text { krvi }\end{array}$ & $\begin{array}{c}\text { Broj } \\
\text { pretraženih } \\
\text { krvi }\end{array}$ & $\begin{array}{c}\text { Broj } \\
\text { pozitivnih } \\
\text { krvi }\end{array}$ \\
\hline Uzgoj & F1 & F2 & F1 & F2 & F1 & F2 & F1 & F2 \\
\hline Rose Bengal test (RBT) & 36 & 24 & 34 & 22 & 2 & $\mathbf{0}$ & 1 & 0 \\
\hline Imunoenzimski test (ELISA) & 36 & 24 & 33 & 23 & 2 & $\mathbf{0}$ & $\mathbf{1}$ & $\mathbf{0}$ \\
\hline
\end{tabular}

F1- farma 1; F2 - farma 2 


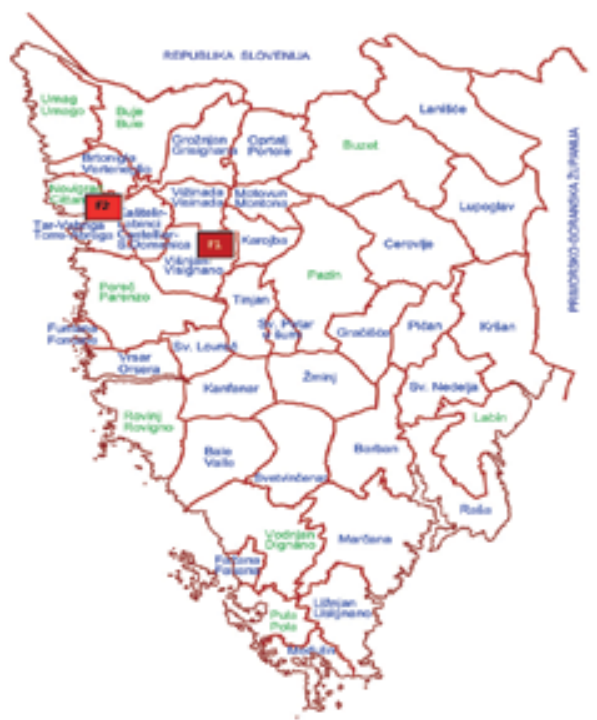

F1- farma 1; F2 - farma 2

Slika 1. Geografski smještaj farmi svinja s potvrđenom brucelozom (infekcija vrstom $B$. suis bv. 2)

testisa i skupnog uzorka limfnih čvorova jednog nerasta te skupnih limfnih čvorova dviju krmača. Molekularnom identifikacijom utvrđena je B. suis bv. 2. $S$ farme 2 na bakteriološku pretragu upućeni su testisi, epididimis i skupni limfni čvorovi nerasta te maternica i skupni limfni čvorovi krmače. Brucela je izolirana iz maternice krmače, a izolat pripada vrsti $B$. suis bv. 2.

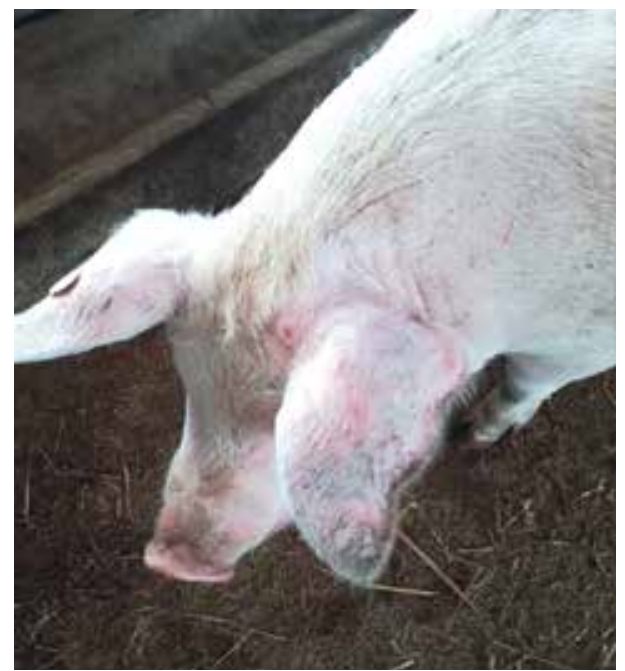

Slika 2. Pozitivna reakcija na brucelin u svinje inficirane vrstom $B$. suis bv. 2

Tijekom 2019. godine s farme 1 na bakteriološku pretragu dostavljen je uterus i skupni limfni čvorovi iz kojih je izdvojena $B$. suis bv. 2, dok su s farme 2 dostavljeni uterusi i skupni limfni čvorovi 12 svinja iz kojih nije izdvojena Brucella sp. (Tabela 2).

\section{Rasprava}

Endemski status B. suis bv. $2 \mathrm{u}$ populaciji svinja u Republici Hrvatskoj potvrđuju ranija istraživanja provedena

Tabela 2. Bakteriološka i molekularna pretraga organa i tkiva svinja

\begin{tabular}{|c|c|c|c|c|}
\hline Godina & Vrsta materijala & $\begin{array}{c}\text { Broj } \\
\text { uzoraka } \\
\text { (farma) }\end{array}$ & $\begin{array}{c}\text { Broj izolata } \\
\text { (farma) } \\
\text { jedan izolat }=1 \\
\text { životinja }\end{array}$ & $\begin{array}{c}\text { Organ/tkivo iz kojeg je } \\
\text { izdvojena Brucella suis } \\
\text { bv. } 2 \\
\text { (broj svinja) }\end{array}$ \\
\hline \multirow[t]{2}{*}{2018.} & \multirow{2}{*}{$\begin{array}{l}\text { Reproduktivni organi, } \\
\text { jetra i limfni čvorovi }\end{array}$} & $11(F 1)$ & $3(F 1)$ & $\begin{array}{c}\text { limfni čvorovi (2); testes } \\
\text { (1) }\end{array}$ \\
\hline & & 2 (F2) & 1 (F2) & uterus (1) \\
\hline \multirow[t]{2}{*}{2019.} & \multirow{2}{*}{$\begin{array}{l}\text { Reproduktivni organi i } \\
\text { limfni čvorovi }\end{array}$} & $1(F 1)$ & $1(F 1)$ & $\begin{array}{c}\text { uterus* (1), In. skupno } \\
\text { (1) }\end{array}$ \\
\hline & & 12 (F2) & 0 & 0 \\
\hline
\end{tabular}

* B. suis je izdvojen iz limfnih čvorova i uterusa iste životinje 
u ekstenzivnim i intenzivnim uzgojima različitih županija. U posljednjih dvadesetak godina bolest je opisana u: Zagrebačkoj, Sisačko-moslavačkoj, Bjelovarsko-bilogorskoj, Požeškoslavonskoj, Brodsko-posavskoj, Virovitičko-podravskoj i Osječkobaranjskoj, Vukovarsko-srijemskoj županiji i Gradu Zagrebu (Cvetnić i sur., 2003., 2005., 2009., 2017., Duvnjak i sur., 2015., Špičić i sur., 2010.). Treba napomenuti da se u razdoblju od 2003. do 2008. godine u konja, domaćih i divljih svinja utvrdila i infekcija varijantom vrste B. suis koju karakterizira rast na hranilištu uz dodatak $20 \mu \mathrm{g} / \mathrm{mL}$ fuchsina što je svojstveno biovaru 3. Molekularnom tipizacijom metodom INgene Bruceladder Suis kit (Ingenasa, Španjolska) utvrđena je pripadnost biovaru 1 , a $s$ obzirom na tradiciju i naviku držanja svinja i mogućnosti prijenosa na ljude po niskom zoonotskom potencijalu najsličniji su biovaru 2 (Cvetnić i sur., 2005., 2009.). Zanimljivo je da nakon 2008. godine navedena varijanta $B$. suis nije više nikada izdvojena u potvrđenim slučajevima bruceloze domaćih i divljih životinja što predstavlja izuzetak $\mathrm{u}$ evoluciji vrste $B$. suis na našim prostorima (Duvnjak i sur., 2015.). Bruceloza svinja najviše je zastupljena na području Sisačko-moslavačke županije, osobito u području uz Park prirode Lonjsko polje, Posavini oko rijeke Save i Slavoniji gdje ekstenzivan način držanja životinja omogućuje kontakt i parenje domaćih i zaraženih divljih svinja. Osim spomenutih, utvrđena je i u većini županija kontinentalne Hrvatske koje graniče s nekoliko europskih zemalja; Slovenijom, Mađarskom, Bosnom i Hercegovinom te Srbijom (Cvetnić i sur., 2008., 2009., 2017., Špičić i sur., 2010.). U evropskim zemljama brucelozu svinja prouzroči vrsta $B$. suis bv. 2 te se infekcije $\mathrm{u}$ domaćih $\mathrm{i}$ divljih svinja redovito opisuju u zemljama centralne i zapadne Europe (Garin-Bastuji, 2000., Godfroid i Käsbohrer, 2002., Leuenberger i sur., 2007., Barlozzari i sur., 2015., Pilo i sur., 2015.).

Iako B. suis bv. 2 nema posebno izraženo zoonotsko značenje, štete koje nanosi svinjogojskoj proizvodnji su velike te pri pojavi bolesti dovodi do trenutne propasti uzgoja pri pojavi bolesti. No, opisan je prijenos na druge životinjske vrste (Ramamoorthy i sur., 2011., Fretin i sur., 2013., Szulowski i sur., 2013., Kin i sur., 2014., Sting i sur., 2014.).

Istra nije tipično svinjogojska hrvatska županija, no malobrojne držatelje svinja kao i veterinarsku službu potrebno je osvijestiti o obvezi prijave svakog slučaja pobačaja kao temeljne mjere nadzora nad brucelozom. Farme u kojima su utvrđeni pobačaji i kasnije potvrđena bruceloza svinja su orijentirane na poluekstenzivno držanje, kombinacijom štalskog držanja i ispusta u okolini farme te je moguć kontakt s divljim svinjama kao prirodnim nositeljima. Da bismo suzbili ovu diljem svijeta rasprostranjenu zoonozu, u dijagnostici, identifikaciji i tipizaciji uzročnika uz serološke i bakteriološke se metode unatrag gotovo dva desetljeća koriste i molekularne metode (OIE, 2018.). Na dva gospodarstva smještena na sjeverozapadnom dijelu Istre tijekom 2018. i 2019. godine serološki su pretražene $62 \mathrm{krvi}$ svinja RBT i ELISA testom, a pozitivno je reagiralo 57 životinja. Zbog sličnosti u građi lipopolisaharida ovojnice stanice Brucella i drugih bakterijskih vrsta od kojih je najznačajnija Yersinia enterocolitica serotip O:9 navedenim se serološkim pretragama često utvrđuju lažno pozitivne reakcije (Jungersen i sur., 2006., Weiner i sur., 2013.). Temeljem epidemiološke situacije $u$ Istri i mogućnosti lažno pozitivnih seroloških reakcija, odlučeno je na ograničenom broju serološki pozitivnih svinja provesti brucelinizaciju aplikacijom proteinskog derivata 
dobivenog ekstrakcijom hrapavog soja vrste Brucella melitensis B115. Naime, primjenom ove dijagnostičke metode moguće je razlučiti infekciju vrstom $B$. suis bv. 2 od lažno pozitivnih seroloških reaktora (Dieste-Perez i sur., 2014.).

Nakon provedene brucelinizacije 8 svinja, na jednoj od farmi tijekom 2018. godine, 7 životinja reagiralo je pozitivno na brucelin $\mathrm{u}$ vidu edema, crvenila, bolnosti i centralne nekroze tkiva. Vođeni ovim rezultatom, žurno je provedeno klanje pozitivnih svinja $\mathrm{s}$ ciljem provođenja bakteriološke pretrage. B. suis je izdvojena iz 5 uzoraka (skupni uzorci limfnih čvorova, testis i uterus). Molekularnom identifikacijom potvrđeno je da se radi o vrsti $B$. suis bv. 2. Ovim pristupom u najkraćem se roku $s$ velikom specifičnošću može potvrditi slučaj infekcije vrstom $B$. suis u uzgoju i postupak suzbijanja bolesti učiniti efikasnim. Obzirom da se radi o prvim potvrdama bruceloze svinja na području Istarske županije, da bi mogli utvrditi izvore zaraze i puteve širenja potrebno je provesti genotipizaciju izdvojenih sojeva vrste $B$. suis primjenom standardnih metoda poput MLVA (engl. multilocus variable number tandem repeats analysis) genotipizacije pomoću 16 lokusa (Al Dahouk i sur., 2005., Le Flèche i sur., 2006.) i MLST (engl. multilocus sequence typing analysis) na 9 lokusa (Whatmore i sur., 2007.) ali i nove platforme sekvenciranja četvrte generacije (MinION ${ }^{\mathrm{TM}}$, Oxford Nanopore Technologies (ONT), Oxford, UK) (Duvnjak i sur., 2022.). Dobivene bismo rezultate tada mogli usporediti $\mathrm{s}$ već utvrđenim genotipovima na području R. Hrvatske i okolnih zemalja (Duvnjak i sur., 2015., 2022.) i prikupiti informacije kako o samom izboju bolesti tako i o geografskoj pripadnosti sojeva, putevima širenja i rizicima za životinje i ljude. Monitoring divljih svinja i zečeva na području Istarske županije mogao bi nam dati odgovore o rasprostranjenosti i rezervoarima bolesti.

\section{Literatura}

1. AL DAHOUK, S., H. TOMASO, E. PRENGERBERNINGHOFF, W. D. SPLETTSTOESSER, H. C. SCHOLZ and H. NEUBAUER (2005): Identification of Brucella species and biotypes using polymerase chain reaction-restriction fragment length polymorphism (PCR- RFLP). Crit. Rev. Microbiol. 31, 191-196. 10.1080/10408410500304041

2. AL DAHOUK, S., P. LEFLECHE, K. NÖCKLER et al. (2007): Evaluationof Brucella MLVA typing for human brucellosis. J. Microbiol. Meth. 69, 137-145. 10.1016/j.mimet.2006.12.015

3. ALTON, G. G., L. M. JONES, R. D. ANGUS and J. M. VERGER (1988): Techniques for the brucellosis laboratory. Paris: Institut National de la Recherche Agronomique.

4. ALTON, G. G. (1990): Brucella suis. In: Animal Brucellosis; Nielsen, K., J. R. Duncan, Eds.; CRC Press: Boca Raton, pp. 411-423.

5. ANDERSEN, F. M. and K. B. PETERSEN (1995) Brucellosis: a case of natural infection of a cow with Brucella suis biotype 2. DanskVeterinaertidsskrift 78, 408.

6. BARLOZZARI, G., A. FRANCO, G. MACRI, S LORENZETTI, F. MAGGIORI, S. DOTTARELLI, M. MAURELLI, E. DI GIANNATALE, M. TITTARELLI, A. BATTISTI and F. GAMBERALE (2015): First report of Brucella suis biovar 2 in a semi free-range pig farm, Italy. Vet. Ital. 51, 151-154.

7. BERGAGNA, S., S. ZOPPI, E. FERROGLIO, M GOBETTO, A. DONDO, E. DI GIANNATALE, M. S. GENNERO and C. GRATTAROLA ( 2009): Epidemiologic survey for Brucella suis biovar 2 in a wildboar (Susscrofa) population in Northwest Italy. J. Wildl. Dis. 45, 1178-1181. 10.7589/0090-3558-45.4.1178

8. CVETNIĆ, Ž., M. MITAK, M. OCEPEK, M. LOJKIĆ, S. TERZIĆ, L. JEMERŠIĆ, A. HUMSKI, B. HABRUN, B. ŠOŠTARIĆ, M. BRSTILO, B. KRT and B. GARINBASTUJI (2003): Wild boars (Sus scrofa) as reservoirs of Brucella suis biovar 2 in Croatia. Acta. Vet. Hung. 51, 465-473. 10.1556/avet.51.2003.4.4

9. CVETNIĆ, Ž., S. ŠPIČIĆ, S. ĆURIĆ, B. JUKIĆ, D. ALBERT, M. THIEBAUD and B. GARIN-BASTUJI (2005): Isolation of Brucella suis biovar 3 from horses in Croatia. Vet. Rec. 156, 584-585. 10.1136/vr.156.18.584

10. CVETNIĆ, Ž., R. VELIĆ, S. ŠPIČIĆ, S. DUVNJAK, M. ZDELAR-TUK, D. MAJNARIĆ and B. ALERAJ (2008): Distribution of brucellosis in the Republic of Croatia with an overview of the situation in Bosnia and Herzegovina. Croat. J. Infect. 28, 117-123.

11. CVETNIĆ, Ž., S. ŠPIČIĆ, J. TONČIĆ, D. MAINARIĆ, M. BENIC, D. ALBERT, M. THIÉBAUD and B GARIN-BASTUJI (2009): Brucella suis infection in domestic pigs and wild boar in Croatia. Rev. Sci. Tech. 28, 1057-1067. 10.20506/rst.28.3.1947

12. CVETNIĆ, Ž., S. DUVNJAK, M. ZDELAR-TUK, I. REIL, M. MIKULIĆ, M. CVETNIĆ and S. ŠPIČIĆ (2017): Swine brucellosis caused by Brucella suis biovar 2 in Croatia. Slov. Vet. Res. 54, 149-154. 10.26873/SVR-360-2017

13. DÍAZ APARICIO, E. (2013): Epidemiology of brucellosis in domestic animals caused by Brucella melitensis, Brucella suis and Brucella abortus. Rev. Sci. Tech. 32, 43-51, 53-60. 10.20506/rst.32.1.2187

14. DIESTE-PÉREZ, L., J. M. BLASCO, M. J. DE MIGUEL, C. M. MARÍN, M. BARBERÁN, R CONDE-ÁLVAREZ, I. MORIYÓN and P. M. MUÑO (2014): Performance of skin tests 
with allergens from B. melitensis B115 and rough B. abortus mutants for diagnosing swine brucellosis. Vet. Microbiol. 161, 161-168. 10.1016/j. vetmic.2013.10.024

15. DUVNJAK, S., I. RAČIĆ, S. ŠPIČIĆ, M. ZDELARTUK and I. REIL (2015): Characterisation of Brucella suis Isolates from Southeast Europe by Multi-LocusVariable-Number Tandem Repeat Analysis. Vet. Microbiol. 180, 146-150. 10.1016/j. vetmic.2015.08.013

16. DUVNJAK, S., Ž. PAVLINEC, R. VASER, K. KRIŽANOVIĆ, M. ŠIKIĆ, M. ZDELAR-TUK, I. REIL and S. ŠPIČIĆ (2022): Efficacy of next-generation sequencing in bacterial zoonoses diagnostics. Vet stn. 53, 1-10. 10.46419/vs.53.1.9

17. EFSA (2009): Scientific opinion of the Panel ofAnimal Health andWelfare (AHAW) on Porcine brucellosis (Brucella suis), on a request from the Commission on porcine brucellosis (Brucella suis). EFSA J. 1-111.

18. FRETIN, D., M. MORI, G. CZAPLICKI, C. QUINET B. MAQUET, J. GODFROID and C. SAEGERMAN (2013): Unexpected Brucella suis biovar 2 infection in a dairy cow, Belgium. Emerg. Infect. Dis. 19, 2053-2054. 10.3201/eid1912.130506

19. GARCIA-YOLDI, D., C. M. MARIN, P. M. DE MIGUEL, P. M. MUNOZ, J. L. VIZMANOS and I. LOPEZ-GONI (2006): Multiplex PCR assay for the identification and differentiation of all Brucella species and the vaccine strains Brucella abortus S19 and RB51 and Brucella melitensis Rev1. Clin Chem. 52, 779-781. 10.1373/clinchem.2005.062596

20. GARIN-BASTUJI, B., J. HARS, D. CALVEZ, M. THIEBAUD, and M. ARTOIS (2000): Brucellose du porc domestique et du sanglier sauvage a Brucella suis biovar 2 en France. Epidemiol. Sante. Anim. 38, 1-5.

21. GODFROID, J. (2002): Brucellosis in wildlife. Rev. Sci. Tech. 21, 277-286. 10.20506/rst.21.2.1333

22. GODFROID, J. and A. KÄSBOHRER (2002): Brucellosis in the European Union and Norway at the turn of the twenty-first century. Vet. Microbiol. 90, 135-145. 10.1016/S0378-1135(02)00217-1

23. GODFROID, J., A. CLOECKAERT, J. P. LIAUTARD, S. KOHLER, D. FRETIN, K. WALRAVENS, B. GARIN-BASTUJI and J. J. LETESSON (2005): From the discovery of the Malta fever's agent to the discovery of a marine mammal reservoir, brucellosis has continuously been a reemerging zoonosis. Vet. Res. 36, 313-326. 10.1051/vetres:2005003

24. GODFROID, J., B. GARIN-BASTUJI, C. SAEGERMAN and J. M. BLASCO (2013): Brucellosis in terrestrial wildlife. Rev. - Off. Int. Epizoot. 32, 2742. 10.20506/rst.32.1.2180

25. GRÉGOIRE, F., B. MOUSSET, D. HANREZ, C. MICHAUX, K. WALRAVENS and A LINDEN (2012): A Serological and bacteriological survey of brucellosis in wildboar (Susscrofa) in Belgium. BMC Vet. Res. 8, 1-8. 10.1186/1746-6148-8-80

26. HARS, J., M. THIEBAUD, C. CAU, S. ROSSI, E. BAUDET, F. BOUÉ and B. GARIN-BASTUJI (2004): La brucellose du sanglier et du lièvre due à Brucella suis 2 en France. Faune sauvage 261, 18-23.

27. JA $\ddot{Y}$, M., M. A. CHERFA, G. LE CARROU, A. DRAPEAU, Y. CORDE, V. MICK and B. GARINBASTUJI (2014): Brucella suis biovar 2 infection in atypical hosts in France. Proceedings of the Brucellosis. International Research Conference, Including the $67^{\text {th }}$ Annual Brucellosis Research Meeting.
28. JUNGERSEN, G., V. SØRENSEN, S. B. GIESE, J. A. STACK and U. RIBER (2006): Differentiation between serological responses to Brucella suis and Yersinia enterocolitica serotype O:9 after natural or experimental infection in pigs. Epidemiol. Infect. 134, 347-357. 10.1017/S095026880500511X

29. KIN, M. S., M. FORT, S. T. DE ESCHAIDE and E. B. CASANAVE (2014): Brucella suis in armadillos (Chaetophractus villosus) from La Pampa, Argentina. Vet. Microbiol. 170, 442-445. 10.1016/j. vetmic.2014.01.039

30. LAGIER, A., S. BROWN, A. SOUALAH, I. JULIER, B. TOURRAND, D. ALBERT, J. REYNES and B. GARIN-BASTUJI (2005): Brucellose aigueà Brucella suis biover 2 chez un chasseur de sanglier Mã@decine Mal. Infect., 35 (suppl. 2), p. S185. 10.1016/S0399-077X(05)81637-3

31. LEDWABA, M. B., C. GOMO, K. E. LEKOTA, P. LE FLĖCHE, A. HASSIM, G. VERGNAUD and H. VAN HEERDEN (2019): Molecular characterization of Brucella species from Zimbabwe. PloS Negl. Trop. Dis. 13, e0007311. doi: 10.1371/journal. pntd.0007311. 10.1371/journal.pntd.0007311

32. LEUENBERGER, R., P. BOUJON, B. THUR, R. MISEREZ, B. GARIN-BASTUJI, J. RUFENACHT and K. D. STARK (2007): Prevalence of classical swine fever, Aujeszky's disease and brucellosis in a population of wild boar in Switzerland. Vet. Rec. 160, 362-368. 10.1136/vr.160.11.362

33. LE FLÈCHE, P., I. JACQUES, M. GRAYON, S. AL DAHOUK, P. BOUCHON, F. DENOEUD, K NÖCKLER, H. NEUBAUER, L. A. GUILLOTEAU, G. VERGNAUD (2006): Evaluation and selection of tandem repeat loci for a Brucella MLVA typing assay. BMC Microbiol. 6, 9-22. 10.1186/1471-2180-6-9

34. MAILLES, A., M. OGIELSKA, F. KEMICHE et al. (2017): Brucella suis biovar 2 infection in humans in France: emerging infection or better recognition? Epidemiol. Infect. 2711-2716. 10.1017/ S0950268817001704

35. MEGID, J., L. A. MATHIAS and C. A. ROBLES (2010): Clinical manifestations of brucellosis in domestic animals and humans. OpenVet. Sci. J. 4, 119-126. 10.2174/1874318801004010119

36. MEIRELLES-BARTOLI, R. B., L. A. MATHIAS and L. E. SAMARTINO (2012): Brucellosis due to Brucella suis in a swine herd associated with a human clinical case in the State ofSão Paulo, Brazil. Trop. Anim. Health Prod. 44, 1575-1579. 10.1007/ s11250-012-0108-2

37. MÜHLDORFER, K., G. WIBBELT, C. A. SZENTIKS, D. FISCHER, H. C. SCHOLZ, M. ZSCHCÖK and T. EISENBERG (2017): The role of 'atypical' Brucella in amphibians: are we facing novel emerging pathogens? J. Appl. Microbiol. 122, 40-53. 10.1111/jam.13326

38. MUNOZ, P. M., M. BOADELLA, M. ARNAL et al. (2010): Spatial Distribution and risk factors of brucellosis in Iberian wild ungulates. BMC Infect. Dis. 10:e46 (14 pp.) ttps://bmc infectdis.biomed central.com/ articles/10.1186/1471-2334-10-46 10.1186/1471-2334-10-46

39. OIE (2018): Brucellosis (Brucella Abortus, B. Melitensis and B. Suis) (infectionWith B. Abortus, B. Melitensis and B. Suis) (NB: Version Adopted in May 2016) in: Manual of DiagnosticTestsandVaccines for Terrestrial Animals 2018. Office International des Epizooties, París, France, pp. 1-44.

40. PATON, N. I., N. W. S. TEE, C. K. F. VU and T. P. TEO (2001): Visceral abscesses due to Brucella Suis 
infection in a retired pig farmer. Clin. Infect. Dis. 32, 1229-1230. 10.1086/319748

41. PILO, C., M. T. TEDDE, G. ORRU, G. ADDIS and M. LICIARDI (2015): Brucella suis infection in domestic pigs in Sardinia (Italy). Epidemiol. Infect. 143, 2170-2177. 10.1017/S0950268814003513

42. POESTER, F. P., L. E. SAMARTINO and R. L. SANTOS (2013): Pathogenesis and pathobiology of brucellosis in livestock. Rev. Sci. Tech. 32, 105-115. 10.20506/rst.32.1.2193

43. RAMAMOORTHY, S., M. WOLDEMESKEL, A. LIGETT, R. SNIDER, R. COBB and S. RAJEEV (2011): Brucella suis infection in dogs, Georgia, USA. Emerg. Infect. Dis. 17, 2386-2387. 10.3201/eid1712.111127

44. SCHOLZ, H. C., Z. HUBALEK, J. NESVADBOVA, H. TOMASO, G. VERGNAUD, P. LE FLĖCHE, A. M. WHATMORE, S. AL DAHOUK, M. KRÜGER, C. LODRI and M. PFEFFER (2008a): Isolation of Brucella microti from soil. Emerg. Infect. Dis. 14, 1316-1317. 10.3201/eid1408.080286

45. SCHOLZ, H. C., Z. HUBALEK, I. SEDLACEK et al. (2008b): Brucella microti sp. nov., isolated from the common vole Microtus arvalis. Int. J. Syst. Evol. Microbiol. 58(Pt 2), 375-382. 10.1099/ijs.0.65356-0

46. SCHOLZ, H. C., K. NÖCKLER, C. GÖLLNER et al. (2010): Brucella inopinata sp. nov., isolated from a breast implant infection. Int. J. Syst. Evol. Microbiol. 60, 801-808. 10.1099/ijs.0.011148-0

47. SCHOLZ, H. C., S. REVILLA-FERNÁNDEZ, S. AL DAHOUK et al. (2016): Brucella vulpis sp. nov., isolated from mandibular lymph nodes of red foxes (Vulpesvulpes). Int. J. Syst. Evol. Microbiol. 66, 2090-2098. 10.1099/ijsem.0.000998

48. SCHOLZ, H. C., M. BANAI, A. CLOECKAERT, P. KAMPFER and A. M. WHATMORE (2018): Brucella. In: Bergey's Manual of Systematics of Archaea and Bacteria, eds. Whitman, W. B., Rainey, F., Kämpfer, P., Trujillo, M., Chun, J., DeVos, P. (Hoboken, NJ:
John Wiley \& Sons, Inc.) 10.1002/9781118960608. gbm00807.pub.

49. STING, R., I.SCHWABE, R. OEHME, M.C. ELSCHNER and F. MELZER (2014): First report of a Brucella suis infection in roe deer (Capreolus capreolus). Berl. Munch. Tierartzl. Wochenschr. 127, 120-122.

50. SZULOWSKI, K., W. IWANIAK, M. WEINER and J. ZLOTNICKA (2013): Brucella suis biovar 2 isolations From cattle in Poland. Ann. Agric. Environ. Med. AAEM 20, 672-675.

51. ŠPIČIĆ, S., M. ZDELAR-TUK, I. RAČIĆ, S. DUVNJAK and Z. CVETNIĆ (2010): Serological, bacteriological, and molecular diagnosis of brucellosis in domestic animals in Croatia. Croat. Med. J. 51, 320-326. 10.3325/cmj.2010.51.320

52. ŠPIČIĆ, S., M.ZDELAR-TUK, I. RAČIĆ, A.VUJNOVIĆ, M. BENIĆ, S. DUVNJAK and Ž. CVETNIĆ (2013) Sensitivity of actual laboratory diagnostic methods used for surveillance of swine brucellosis in Croatia. Int. J. Appl. Res.Vet. Med. 11, 167-173.

53. ŠPIČIĆ, S., M. BENIĆ, M. ZDELAR-TUK, S DUVNJAK, A. KARAKAŠ, T. KIŠ, I. SUČEC and Ž. CVETNIĆ (2016): Brucellosis in Turopolje pig breeding in the 2008-2011 period: an overview of laboratory diagnostic and eradication system. Vet. arhiv 86, 243-252.

54. WEINER, M., K. SZULOWSKI and W. IWANIAK (2013): The porcine brucellosis-evidence of the role of Yersinia enterocolitica O:9 in occurrence of false positive serological reactions Pol. J. Vet. Sci. 16, 129130. 10.2478/pjvs-2013-0019

55. WHATMORE, A. M., L. L. PERRETT and A. P. MACMILLAN (2007): Characterisation of the genetic diversity of Brucella by multilocus sequencing. BMC Microbiol. 7, 34-48. 10.1186/1471-2180-7-34

56. WHATMORE, A. M. (2014): Ancient-pathogen genomics: coming of age? mBio. 5, e01676-14 doi: 10.1128/mBio.01676-14

\section{Review of cases of swine brucellosis in Istria during 2018 and 2019}

Maja ZDELAR-TUK, DVM, PhD, Silvio ŠPIČIĆ, DVM, PhD, Sanja DUVNJAK, BSc, PhD, Irena REIL, DVM, PhD, Gordan KOMPES, DVM, PhD, Boris HABRUN, DVM, PhD, Croatian Veterinary Institute, Zagreb, Croatia; Slobodan MUDRIĆ, DVM, MSc, Ministry of Agriculture, Croatia

Swine brucellosis has been considered an endemic disease in Croatia for two decades, especially in continental areas characterized by pig production, both intensive and extensive. Furthermore, cases of the disease are regularly reported throughout Central and Western Europe. During 2018 and 2019, swine brucellosis caused by the species $B$. suis bv. 2 was confirmed on two pig farms located in northwestern Istria, as the cause of pig abortion and during controls of neighbouring herds. Diagnosis of the disease was performed by serological tests, Brucella skin intradermal test, bacteriological and molecular tests. To our knowledge, this is the first described case of brucellosis in domestic pigs in a coastal Croatian county and proof of the need for mandatory control of this disease in cases of abortion. Since no herds carry the official status of being free of swine brucellosis in the Republic of Croatia, from the safety perspective, breeders should introduce prior control of the animal and its breeding origin, and seek guarantees for this disease. Furthermore, considering the growing popularity of extensive methods of pig breeding, disease monitoring in wild animals would determine the risks and importance of transmission to domestic pigs in certain Croatian regions.

Key words: Brucella suis; brucellosis; swine; Istria; epidemiology 